\title{
Comunicação, mídia e processos de democracia local: estratégias de aproximação entre governo e cidadãos
}

\begin{tabular}{c}
\hline \hline Angela Cristina Salgueiro Marques \\
Programa de Pós-Graduação em \\
Comunicação Instititucional \\
Universidade Nove de Julho \\
\hline \hline
\end{tabular}

\begin{abstract}
Resumo: As relações entre comunicação, mídia e democracia local são discutidas a partir da análise da campanha "Quem gosta de BH tem seu jeito de mostrar", lançada pela prefeitura da cidade de Belo Horizonte, em maio de 2003. Duas hipóteses distintas originam-se de uma imagem ideal de participação política que guia a campanha. Por um lado, a campanha enfatiza uma divisão de tarefas entre os cidadãos que teria como função melhorar a qualidade de vida da cidade. Por outro lado, ela impõe uma restrição à participação política oferecendo aos cidadãos um falso status de colaboradores no processo de resolução dos problemas coletivos. O uso estratégico da mídia cria uma sensação de proximidade entre o governo municipal e os cidadãos, embora um processo real de deliberação não ocorra entre os habitantes, ou entre esses e os atores institucionais. A política discursiva da campanha reside em designar atores e ações específicas, assinalando suas contribuições ao bem-coletivo como um caminho capaz de gerar uma coesão política e cultural interna na cidade.
\end{abstract}

Palavras-chave: democracia local; participação; mídia; esfera pública; campanha publicitária

Abstract: The relations among communication, mass media and local democracy are analysed here from an empirical case of the Belo Horizonte's Prefecture. In May 2003 the Prefecture started a publicity campaign entitled Who likes BH, has one's own way to show it (Quem gosta de BH tem seu jeito de mostrar). Two distinct assumptions arise from an ideal image of political participation that guides the campaign. In one hand the campaign claims for a division of tasks among citizens that would improve the life qualityin the city. In the other hand it imposes a restriction to political participation by giving to citizens the false status of collaborators in solving colctive problems. The strategic use of mass media creates a sensation of proximity between municipal government and citizens while a real deliberation process does not take place among the inhabitants. The campaign policy discourse assigns specific actors and actions, underlining their contributions to collective good as a path to generate internal political and cultural cohesion within the city.

Keywords: local democracy; participation; mass media; public sphere; publicity campaign 


\section{Introdução}

Experiências concretas têm nos revelado que, cada vez mais, governantes e governados têm estabelecido relaçãos de proximidade e de diálogo, seja através de uma iniciativa que parte da institucionalidade vigente, seja por meio da organização e mobilização da sociedade civil. Estudos sobre o Orçamento Participativo (AVRITZER \& PEREIRA, 2002), os Conselhos de Políticas Públicas (PEREIRA, 2000; GOHN,2001; OLIVEIRA, 2004; TEIXEIRA, 2000), as rádios e televisões comunitárias (COGO, 1998; OLIVEIRA, 2002) apresentam análises que apontam para uma tendência crescente de criação de espaços de debate entre governantes e cidadãos.

Tais espaços deveriam assumir a forma da esfera pública descrita por Habermas, a qual tem como principal característica o fato de se constituir em um "meio de comunicação isento de limitações, no qual é possível captar melhor novos problemas, conduzir discursos expressivos de entendimento recíproco e articular, de modo mais livre, identidades coletivas e interpretações de necessidades" (HABERMAS, 1997, p.33). Se, de um lado, essas práticas discursivas de negociação entre governantes e governados realizadas na esfera pública podem ser tomadas como positivas e transformadoras, de outro lado, é preciso grande cuidado ao avaliarmos como essas mudanças participativas estão ocorrendo. Acreditamos ser necessário observar criticamente as estratégias discursivas dos atores políticos que, em nome de uma maior proximidade com os cidadãos, têm investido em uma comunicação pública assentada sobre princípios democráticos como a participação e a coautoria das decisões.

Neste artigo, nos propomos a traçar relações entre a comunicação, a mídia e os processos de construção da democracia local a partir da análise da campanha publicitária "Quem gosta de BH tem seu jeito de mostrar", lançada pela Prefeitura de Belo Horizonte no ano de 2003. Com a análise dessa campanha, pretendemos evidenciar que, através de uma representação idealizada da cidade, o poder local dissolve iniciativas populares em uma "tela" na qual o registro é um tipo de participação convertido em mutirão pelo bem-estar coletivo. A cidade, transformada em cartão postal, não reflete ações políticas voltadas para a participação cívica e para uma partilha responsiva de poder. O que se vê é a exaltação de contribuições particulares para a manutenção de sua memória afetiva e estética. A ênfase conferida ao belo impõe obstáculos a uma potencial reflexão crítica acerca da inserção política do cidadão nos espaços públicos de discussão e de debate. $\mathrm{Na}$ campanha, o cidadão é retratado ora como destaque contra um pano de fundo de espaços plenos de beleza, ora como o próprio pano de fundo para a exposição das ações do governo.

Assim, nosso objetivo principal é, a partir da análise de conteúdo das peças publicitárias da campanha, do site a ela destinada e dos depoimentos que cidadãos 
MARQUES, A. C. S. Comunicação, mídia e processos de democracia...

belo-horizontinos que aí se encontram, revelar as disparidades e tensões existentes entre as falas desses cidadãos e do governo municipal que se autodenomina democrático-popular - e que se serve do discurso da participação ativa dos habitantes nos processos de planejamento de políticas urbanas -, mas que, na prática, destitui os cidadãos de uma autonomia política e de uma capacidade de intervenção pública, dissolvendo-os no cenário estético de uma cidade ideal. Para tanto, combinamos uma análise dos propósitos da campanha com a análise de conteúdo: a) das peças publicitárias a ela dedicadas e b) dos depoimentos de cidadãos feitos no site oficial da campanha.

Partimos da hipótese de que campanhas como essa, ou seja, campanhas que não desafiam divisões pré-estabelecidas de tarefas e lugares entre indivíduos, empresas e instituições, não conduzem a uma efetiva partilha do poder e, portanto, desestimulam o real envolvimento dos cidadãos nos problemas mais preementes da cidade que habitam.

\section{Participação e democracia local}

Segundo Elenaldo Teixeira, o conceito de participação está "impregnado de um conteúdo ideológico e vem sendo utilizado de várias maneiras, seja para legitimar a dominação mediante estratégias de manipulação, seja para negar qualquer papel da institucionalidade em uma idealização de sociedade autônoma, corroborando a visão da sociedade contra o Estado" (TEIXEIRA, p.36, 2000). Assim, a noção de "participação" pode tanto ser usada para maquiar uma falsa promessa de integração da perspectiva dos governados aos processos de debate e de tomada de decisão quanto para caracterizar ações concretas de efetiva consideração dos pontos de vista e opiniões dos cidadãos em processos deliberativos formais. Um exemplo dessa ambiguidade encontra-se nas ações dos conselhos consultivos que, criados pela institucionalidade municipal, são encarregados de colher o aval da sociedade civil sobre determinada política pública - previamente discutida e mesmo aprovada -, pouco enfatizando o debate e a negociação. Nesse sentido, a participação dos cidadãos comuns nas práticas locais de tomada de decisão política, processo fundamental para que a democracia se consolide, transformou-se atualmente em um conceito fluido e pouco preciso, sendo utilizado inclusive para caracterizar processos que independem do envolvimento dialógico e corresponsável dos cidadãos.

A democracia, entendida como um modelo institucional que permite a diferentes grupos sociais alcançarem voz política e igual respeito no plano público, só se concretiza quando há a criação de mecanismos de partilha do poder (BOHMAN,1996; BLONDIAUX,1999). O engajamento cívico dos cidadãos depende, portanto, da consciência individual e coletiva de que os rumos de uma comunidade, 
de uma cidade ou de uma localidade dependem de uma corresponsabilidade sobre o destino do espaço em que vivem e que transformam cotidianamente. Considerar a democracia como esse ideal de poder partilhado entre governantes e governados requer uma reflexão sobre as possibilidades e constrangimentos que esse ponto de vista permite entrever.

Um dos principais dilemas que se colocam hoje para o exercício da democracia diz respeito ao modo como o poder deve ser distribuído e exercido cotidianamente para permitir a convivência entre "desiguais" no plano político (DAGNINO, 2002). Tal problema fica ainda mais evidente quando nos concentramos nos processos de partilha do poder em contextos de democracia local. Primeiro, porque a democracia em contextos locais é tomada como o emblema da possibilidade de uma revitalização da política e de seus processos nos moldes da ágora grega. Nessa perspectiva, a democracia local aparece envolta em uma "aura" de autenticidade e renovação, como se suas formas atuais nada mais fossem do que um duplo perfeito da democracia que prima pela "igualdade" deliberativa de seus membros. E segundo porque a democracia local está sedimentada em valores tais como proximidade, diálogo, confiança e transparência.

De acordo com Dominique Wolton, além de uma missão de refundação da política, estaria atrelada ao "local" a falsa percepção de que "na escala local, que é uma escala humana, nós nos conhecemos e nos compreendemos" (WOLTON, p.90, 2000). As virtudes do local resultam, assim, de uma pretensa ausência de complexidade solucionada pelas relações de proximidade que todos mantêm entre si e com os governantes ${ }^{1}$. Mas essas relações não eliminam a predominância do poder representativo, que age muitas vezes sem considerar possibilidades de construção de articulações comunicativas entre governo e cidadãos.

Atento a esse problema, Alain Bourdin chama a atenção para uma contradição intrínseca da democracia local, uma vez que "essa democracia tem-se ocupado muito também dos pobres, com experiências notáveis, mas às vezes impondo a eles que se ocupem apenas de seus problemas de pobres" (BOURDIN, p.12, 2001). Essa concepção restringe o leque de problemas acerca dos quais certas parcelas da população podem opinar, pervertendo o sentido cooperativo da participação em contextos de democracia local. Entretanto, ela aponta também que a democracia representativa ainda coloca entraves significativos para a consolidação da democracia participativa. Isso fica claro quando percebemos que, apesar de experiências participativas postas em prática em muitas cidades brasileiras, as decisões ainda são tomadas por elites políticas que se reúnem em

\footnotetext{
${ }^{1}$ Entretanto, é o próprio Wolton quem nos adverte de que o local não pode ser mais pensado como refúgio autônomo da política, uma vez que o local não está desvinculado do regional, do nacional e do internacional, ou seja, há uma interdependência entre esses níveis, de modo a conferir complexidade a cada um deles.
} 
MARQUES, A. C. S. Comunicação, mídia e processos de democracia...

esferas de discussão de pouca visibilidade e publicidade para definirem como as pessoas devem se vincular ou se "encaixar" nos processos decisórios (DAUVIN, 2002).

Para teóricos do elitismo democrático (tecnocracia), como Schumpeter (1971), não cabe ao público de cidadãos tomar parte nas discussões políticas a respeito de problemas coletivos. Segundo esse autor, as "massas" agem de acordo com suas paixões e sentimentos, deixando de lado a racionalidade necessária à deliberação². Contudo, autores ligados à uma concepção pluralista da democracia acreditam na capacidade reflexiva e na autonomia dos cidadãos para se constituírem como indivíduos moralmente capazes de elaborar argumentos que sustentem suas posições, assim como de refutarem questionamentos acerca dos pontos de vista por eles adotados (PORTO, 2003; MAIA; 2004; HABERMAS, 1990; AVRITZER, 2000).

Nesse sentido, a democracia local deve ser entendida como um processo de grande complexidade. Ela não é um modelo dado ou predefinido de como cada um deve atuar para solucionar questões políticas e problemas coletivos, mas, sim, um processo tenso e conflituoso no qual atores políticos e sociais se expressam e negociam suas posições na esfera pública nos momentos em que são chamados a elaborar novos entendimentos e/ou soluções rápidas para problemas que atingem a coletividade (STEWART, 1996; AUBELLE, 1999). Segundo Bourdin, a democracia local "é associada à boa governança, quer dizer, à arte de articular todos os atores locais, públicos ou privados, políticos, econômicos, sociais à ação coletiva pelo bem comum" (BOURDIN, 2001, p.11). Mas a arte de reunir múltiplos atores e suas diferentes reivindicações e pontos de vista em torno de uma causa coletiva exige de nós sérias considerações, sobretudo, no que tange ao papel da comunicação e da mídia nos processos de democracia local.

Para que os problemas que afetam grupos e indivíduos sejam formulados em termos coletivos, é preciso que haja uma estrutura de negociação e diálogo a fim de que, através da troca reflexiva de pontos de vista, esses atores possam chegar à um entendimento mútuo acerca daquilo que os aflige (COSTA, 1997; GUTMANN e THOMPSON, 2002). Essa estrutura comporta dois elementos principais: espaços públicos de debate e os meios de comunicação. Assim sendo, uma democracia local não pode se consolidar enquanto a comunicação entre os cidadãos - e entre esses e seus governantes - não estiver assegurada por espaços públicos híbridos ${ }^{3}$ de discussão e instrumentos mediadores que facilitem a

\footnotetext{
2 De acordo com Schumpeter, "o cidadão típico desce para um nível inferior de rendimento mental logo que entra no campo político. Argumenta e analisa de uma maneira que ele mesmo imediatamente reconheceria como infantil na sua esfera de interesses reais. Torna-se primitivo novamente. 0 seu pensamento assume o caráter puramente associativo e afetivo" (SCHUMPETER, 1971, p.319).

3 Os espaços públicos híbridos são caracterizados por Maria de Lourdes Dolabela Pereira e Leonardo Avritzer como aqueles que congragam atores provenientes das esferas governamentais, comunitárias,
} 
produção de articulações comunicativas entre uma pluralidade de grupos e indivíduos.

A democracia local é construída cotidianamente por uma comunidade que não cessa de se interrogar sobre seu futuro (AUBELLE, 1999). Portanto, a comunicação - aqui entendida não só como meios de comunicação, mas como um processo intersubjetivo destinado a construir vínculos entre os indivíduos e instituições - possui um papel crucial tanto para aproximar os cidadãos e grupos que compõem a sociedade civil quanto para estabelecer conexões com as esferas formais de poder. Nesse contexto, a mídia, além de diponibilizar a esses atores informações as mais diversas, executa um papel de interfece, configurando-se no espaço público de troca dialógica entre governantes e governados (MÉGARD, 2002; MAIA, 2004).

É preciso, então, que façamos uma distinção entre as políticas comunicativas traçadas pelo poder municipal (a prefeitura) e a comunicação pública política desenhada e formada nos processos em que a própria comunidade toma a iniciativa de criar vínculos dialógicos entre seus membros e entre esses e o governo local. No caso das políticas comunicativas desenvolvidas pelas prefeituras, temos uma crescente profissionalização das assessorias de imprensa que produzem informes, jornais, revistas, cartilhas, panfletos e campanhas de grande fôlego, visando consolidar a imagem do prefeito, da cidade e das políticas sociais em desenvolvimento (PAILLIART, 2000). Em contraposição, a comunicação pública política desenvolvida pelas rádios comunitárias, por exemplo, marca uma iniciativa popular de consolidação de laços de participação e cidadania entre grupos e indivíduos.

É preciso deixar claro que esse trabalho não tem como objetivo fazer uma análise detalhada da campanha publicitária da prefeitura de Belo Horizonte. Pelo contrário, pretendemos, a partir da campanha, revelar as assimetrias das relações entre o governo municipal e a sociedade civil. Procuramos identificar as tensões que se estabelecem entre a concepção de participação construída pelo poder público e a participação enquanto negociação cooperativa que depende do fortalecimento de estruturas comunicativas para conferir poder decisório - sobre todas as questões de interesse coletivo - a amplos setores sociais.

cívicas, institucionais, empresariais, etc. Ou seja, são espaços que promovem o encontro entre uma pluralidade de agentes que se comprometem em levar em consideração tudo aquilo que for dito ou proferido pelos demais, de modo a agir de forma cooperativa (AVRITZER e PEREIRA, 2002). Exemplos significativos de fóruns híbridos de deliberação são os Conselhos de Políticas Públicas e os fóruns do Orçamento Participativo. 
MARQUES, A. C. S. Comunicação, mídia e processos de democracia...

\section{A comunicação em contextos locais: entre a ação estratégica e a ação comunicativa}

A democracia local não se configura como uma alternativa ao problema da representatividade, mas evidencia a necessidade de articulações comunicativas entre representantes e representados (BOURDIN, 2001). Nesse sentido, os meios de comunicação têm se apresentado como elemento primordial para uma tentativa de aproximação entre esses dois atores sociais. Para Dominique Mégard (2002), são as novas possibilidades trazidas pela mídia que colocam em evidência o local e suas novas realidades. Contudo, ela ressalta que a internet, os jornais e revistas da municipalidade, os programas de rádio, etc., são técnicas ou instrumentos "insuficientes para refundar o simbólico e o político, ou para resolver a questão da mediação, que é, a princípio, humana e institucional antes de ser técnica" (MÉGARD, 2002, p.40).

Segundo Christian Le Bart (2002), os governantes eleitos devem estruturar planos de comunicação estratégica de modo a conferir visibilidade e transparência aos seus atos e às políticas públicas por eles adotadas. Mégard também defende que os governantes devem estabelecer um plano de comunicação externo e interno, de modo a posicionar a comunicação como recurso estratégico "que permite a informação e a expressão do cidadão, ao mesmo tempo pelos meios humanos e técnicos" (MÉGARD, 2002, p.40). Sabemos que é impossível o estabelecimento da democracia local sem veículos comunicacionais que nos informem sobre as atividades dos políticos, seus projetos, suas intenções e seus feitos. Entretanto, para que a democracia local não se restrinja à prestação de contas dos governantes, é necessário estabelecer uma distinção entre duas formas de comunicação que se estabelecem em nível local: a) a comunicação pública, que é, ao mesmo tempo, institucional, estratégica e dialógica, e b) a comunicação expressa na ação de indivíduos que ancoram sua ação na atividade dialógica de produzir um entendimento mútuo acerca de algo no mundo em que vivem (HABERMAS, 1987).

A comunicação pública consiste em uma "ferramenta de educação cívica, de produção do vínculo social, do território, da história local, reforçando, através de uma informação multiforme, o sentimento de pertencimento a um território comum, e restabelecendo uma proximidade real entre a municipalidade e os cidadãos" (MÉGARD,2002, p.42). É importante destacar que a comunicação pública não pode se restringir à persuasão estratégica ou ao fluxo de mensagens institucionais que, hierarquizadas, partem das esferas governamentais para atingir cidadãos que não encontram espaços de interlocução com seus dirigentes. A comunicação pública deve ser tomada como um processo de diálogo, negociação e tomada de decisões 
que se desenvolve em uma esfera pública que engloba Estado, governo e sociedade (MATOS, 2006).

As mídias que melhor representam a comunicação pública são os jornais locais ou aqueles jornais feitos pela prefeitura, os panfletos, revistas e, principalmente, os sites institucionais na internet. Entretanto, a mídia sozinha não constrói a democracia local. Ao lado dos veículos informativos produzidos pela municipalidade deve existir uma sociedade civil vibrante capaz de articular-se e de refletir sobre as informações disponibilizadas pela prefeitura. No entanto, a comunicação pública apresenta-se muitas vezes como retrato de políticas comunicacionais estratégicas, abrigando uma intencionalidade típica dos sistemas:

\begin{abstract}
"Antes de expressarem um ideal político (a ágora grega), os boletins municipais deveriam concretizar um ideal administrativo: fazer com que as ações se tornem visíveis, partilhar um projeto urbano, dar a ver uma equipe atenta às demandas sociais presentes no âmbito local e que se mostra devidamente preparada para resolver os problemas identificados pelos cidadãos" (LEBART, 2002, p.46).
\end{abstract}

A comunicação estratégica elaborada pelo governo local visa determinados fins que, não raro, independem do diálogo com os cidadãos. Mostrar transparência e eficiência, além de construir uma unidade territorial e identitária da cidade, com as quais todos possam se identificar, suplanta muitas vezes a preocupação de investir em uma forma de comunicação que se estabelece em espaços informais do cotidiano ${ }^{4}$, onde a ação comunicativa opera. De acordo com Habermas, tal ação visa a busca do entendimento recíproco e se produz através da troca não coercitiva de razões entre parceiros que, ao remeterem a um horizonte compartilhado de valores, tradições, normas e experiências, podem chegar a um acordo por meio da linguagem (HABERMAS, 1987, p.152).

Se identificarmos a ação estratégica como sendo o modo de agir dos governantes no subsistema administrativo, e a ação comunicativa como o modo de interlocução vigente nos contextos informais do cotidiano, chegaremos à seguinte indagação: como fazer com que contextos institucionais e informais de conversação e debate se articulem comunicativamente? Para Habermas, essa reconciliação só é possível se considerarmos o poder não como uma força previamente definida, mas como algo definido no conflito argumentativo. O poder compartilhado configura-se, então, como um poder gerado comunicativamente através da criação de fluxos

\footnotetext{
4 Para Louis Quéré, a intercompreensão entre os indivíduos deve ser assegurada "pela possibilidade dos parceiros de mobilizarem tacitamente esquemas de interpretação e definições comuns de fatos e eventos; de fazer referência às mesmas estruturas normativas e mesmas regras de uso; e de se assegurar sobre a capacidade de cada indivíduo em assumir sua identidade pessoal" (QUÉRÉ, 1989, p.26).
} 
dialógicos entre instâncias do governo, especialistas e instâncias da comunidade, as quais expõem e justificam publicamente suas necessidades, posições e pontos de vista (HABERMAS, 1990, p.109 e 111).

Diante de tais considerações, fica clara a necessidade de investigarmos com maior cautela os modos de aproximação discursiva e argumentativa entre governo e cidadãos no contexto local. Sobretudo porque a partilha do poder nem sempre acompanha a inclusão dos cidadãos nos processos de deliberação sobre políticas públicas, principalmente se essa partilha estiver marcada por uma cultura política autoritária e clientelista. Na verdade, tanto governantes quanto governados precisariam assumir responsabilidades democráticas ligadas a um entendimento da participação como uma atividade conjunta de colaboração recíproca. Porém, o que ocorre é que, muitas vezes, projetos de descentralização e de participação popular, ao invés de mobilizarem a população, colocam-na como "pano de fundo" de um cenário de mudanças pretendidas. Isso faz com que os cidadãos não sejam os protagonistas das mudanças, mas coadjuvantes que, ou atuam isoladamente, ou se servem das ações postas em prática pelo governo. Com isso, o afastamento dos cidadãos de processos de negociação e debate acerca de políticas públicas tende a provocar apatia e desconfiança.

\section{O uso estratégico da mídia pelo poder local}

A campanha "Quem gosta de BH tem seu jeito de mostrar", lançada pela Prefeitura de Belo Horizonte (BH) no dia 16 de maio de 2003, tinha como principal objetivo mostrar que, em Belo Horizonte, as articulações entre agentes do governo, empresas do setor privado e sociedade civil estavam sendo consolidadas em prol da melhoria da qualidade de vida da cidade ${ }^{5}$ :

"[A campanha se caracteriza por ser] um grande movimento, que reúne poder público, empresas e cidadãos. É um movimento de cidadania, pela ação conjunta, pela consciência social, por uma atitude cada vez mais humana e solidária. De todos. Uma corrente pelas boas iniciativas e pela participação comunitária. Um mutirão de forças e idéias pela qualidade da vida em nossa cidade, pela sua dignidade.

\footnotetext{
${ }^{5}$ A campanha configurou-se em três etapas. A primeira etapa, marcada pelo slogan "A BH que a gente quer", caracterizou-se pela intensa divulgação na mídia de peças publicitárias que alertavam os cidadãos para a necessidade de participarem de um movimento em prol da melhoria da qualidade de vida de $\mathrm{BH}$. A segunda etapa foi marcada pela comemoração dos 106 anos da capital mineira e, com isso, os habitantes foram convocados a registrar no site da campanha "cinco motivos" para gostar de $\mathrm{BH}$. Posteriormente, algumas opiniões previamente selecionadas foram agrupadas em um livro. E a terceira etapa procurava mostrar como as várias atuações da Prefeitura na cidade estavam presentes na vida de seus moradores. Em todas as etapas, privilegiou-se a rotina de ação de pessoas "comuns", e em quê essa ação seria útil para a cidade.
} 
Um movimento que é o alicerce de uma construção de uma cidade melhor. Para todos $6 . "$

O movimento iniciou-se, assim, sob a forma de um grande "mutirão de ideias" potencialmente capazes de resgatar grandes parcerias e fazer com que todos "participassem", por meio de pequenos gestos rotineiros, da construção de uma "BH que a gente quer". Contudo, duas questões merecem ser feitas : 1) quais são os indivíduos que compõem essa coletividades denominada de "a gente" ? Os atores políticos idealizadores da campanha, ou o povo de $\mathrm{BH}$ ?; e 2) o que seria essa BH que "a gente" quer? Essas questões apontam para algumas clivagens (e não aproximações) entre, primeiro, os projetos da população e da municipalidade relativos aos "usos" possíveis de espaços da cidade de BH. Segundo, entre os desejos de participação dos habitantes da cidade e os projetos de incentivo à inclusão popular (pretensamente participativos). E, terceiro, entre uma "BH que aí está" e uma "BH idealizada e perfeita" - isenta de crimes, pacata, ordeira, bela, inquestionavelmente previsível. Foi essa cidade "aprisionada" entre o ideal e o real que foi retratada pelas peças de publicidade - criadas pelas agências Lápis Raro e Asa - estampadas em outdoors, rádios, canais de televisão, revistas e jornais, e no endereço eletrônico da campanha (www.pbh.gov.br/quemgostadebh), nas quais a Prefeitura de $\mathrm{BH}$, além de expor projetos de responsabilidade social da qual era parceira, criava um espaço para a palavra dos cidadãos, associações, empresas e instituições.

O site oficial da campanha encarregou-se de mostrar que as ações de alguns desses cidadãos poderiam repercutir nas providências tomadas pela prefeitura. Em determinado espaço do site, os internautas eram convidados a expressar seus sentimentos com relação à cidade e a divulgar seu "jeito" de preservá-la. Mas a campanha ganhou destaque com as peças publicitárias que utilizavam verbos ligados a um sentido de participação cívica como, por exemplo, Acreditar, Participar, Limpar, Viver, Preservar, Apoiar, Cuidar, Sorrir, Brincar, Construir, Plantar, Guardar, etc.

\footnotetext{
${ }^{6}$ Ver site da campanha: <www.pbh.gov.br/quemgostadebh>, no link « Conheça a campanha - o que é?".
} 
Figura 1

\section{Peças publicitárias veiculadas em outdoors}
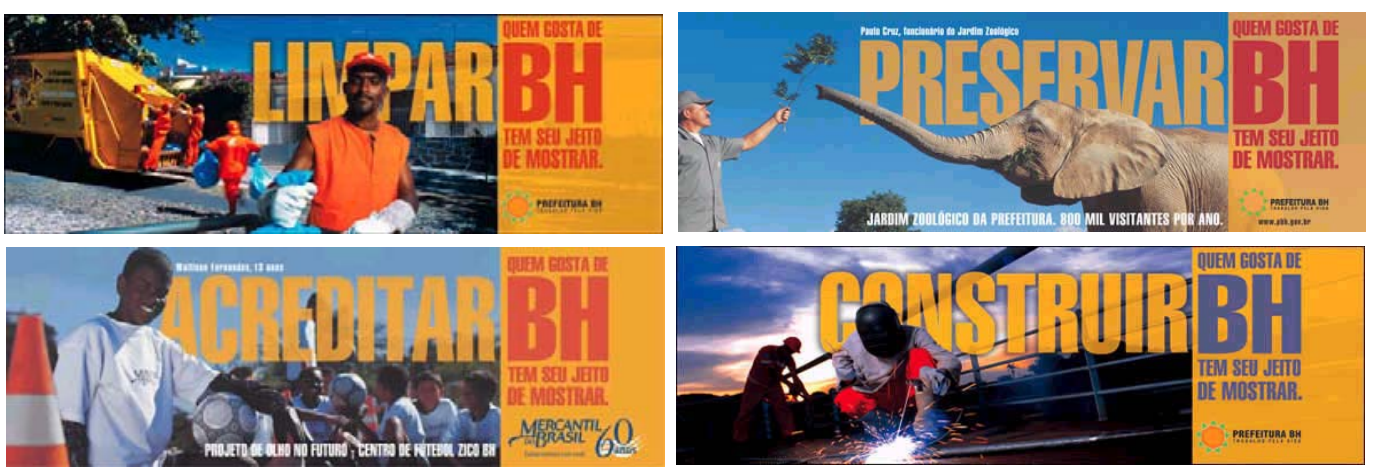

Fonte: <www.pbh.gov.br/quemgostadebh>

Cada um desses verbos é relacionado a um indivíduo específico, cuja trajetória de vida reflete suas ações em prol da cidade e do bem-comum. Todavia, argumentamos que as peças publicitárias refletem um apagamento do real sentido das ações de cada cidadão e uma valorização das obras do governo local. Como exemplo, podemos citar o caso do engenheiro Valdir Teixeira, personagem principal do filme ConstruirBH. Para o então prefeito de Belo Horizonte, Fernando Pimentel (PT), "essa pessoa simboliza o que nosso governo tem feito pela cidade na área de obras e intervenções urbanas ${ }^{7}$." O depoimento do Prefeito deixa claro que o engenheiro foi privado de sua própria história para tornar-se um símbolo da atitude de prestação de contas da prefeitura. Tal postura nos leva a considerar que essas propagandas, além de tentarem aplainar o verdadeiro significado das relações que as pessoas têm com a cidade, transformam essa última em um mapa, ou roteiro capaz de sinalizar, a diferentes públicos, as ações realizadas pela prefeitura.

Além disso, assinalamos ainda a substituição do discurso participativo - que sustenta os propósitos da campanha - por um discurso destituidor, ou seja, as pessoas que moram na cidade são destituídas de sua história, das contribuições específicas que trazem para a cidade e de uma capacidade de formular, expressar e defender suas próprias opiniões, visto que essas últimas são substituídas seja por belas paisagens, seja pelas palavras oficiais.

De modo a tornar evidente essa substituição discursiva, procedemos a uma análise do conteúdo de documentos, páginas da prefeitura na internet ligadas à campanha, revistas, cartilhas e folders produzidos pela prefeitura de $\mathrm{BH}$. O objetivo

7 Ver "Engenheiro é personagem de vídeo da campanha Quem gosta de BH tem seu jeito de mostrar, 29/05/2003" "Banco de Notícias » do site da prefeitura:<www.pbh.gov.br/quemgostadebh>. 
dessa análise estava, particularmente, nos argumentos oficiais focados nas ações de engajamento cívico dos cidadãos.

Além dessa pesquisa documental, fizemos uma análise de conteúdo das peças publicitárias das campanhas concentrando-nos: a) nas imagens de $\mathrm{BH}$ escolhidas para revelar o envolvimento dos cidadãos na reconstrução e preservação dos espaços urbanos; e b) nas narrativas construídas para cidadãos específicos, assim como a ação particular a eles associada (cuidar, participar, construir, etc.). Como exemplo, destacamos o texto da propaganda cujo tema era Educar $\mathrm{BH}$ :

Figura 2

Peça publicitária veiculada na Revista Encontro (Junho, 2003)

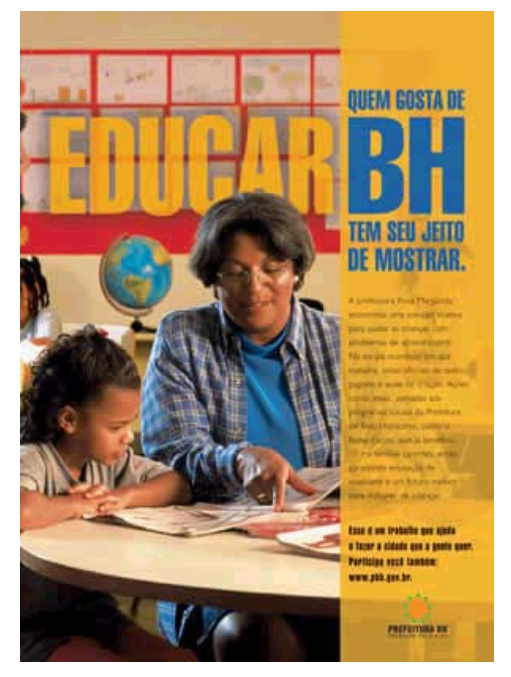

"A professora Rosa Margarida encontrou uma solução criativa para ajudar as crianças com problemas de aprendizagem. Na escola municipal em que trabalha, criou oficinas de teatro, música e aulas de criação. Ações como estas, somadas aos programas sociais da Prefeitura de Belo Horizonte, como o Bolsa Escola, que já beneficia 10 mil famílias carentes, estão garantindo educação de qualidade e um futuro melhor para milhares de crianças. Esse trabalho ajuda a fazer a cidade que a gente quer. Participe você também."

Em nossas análises, procuramos ver se o que é valorizado são as ações dos cidadãos, suas contribuições para a cidade, ou se eles simplesmente desaparecem por trás de um discurso que visa divulgar as obras do governo. O intuito era mostrar 
MARQUES, A. C. S. Comunicação, mídia e processos de democracia...

como as narrativas pessoais não se entrelaçam com as narrativas coletivas (evidenciando um desejo coletivo de uma cidade melhor), e como a participação cívica se trasforma em discurso esvaziado diante da necessidade de anunciar as ações implementadas pela prefeitura. Assim, procuramos identificar de que maneira diferentes discursos conviviam dentro de uma mesma peça. O texto da peça ora destacado nos revela a tensão entre, de um lado, uma narrativa imagéticotextual sobre a "personagem-cidadã" Rosa Margarida destacando sua participação cívica na área educacional e, de outro lado, uma narrativa de divulgação da prefeitura ostentando um de seus maiores programas sociais.

Não desconsideramos o fato de que possuir um nome e de "ser contado como parte integrante da constituição simbólica da cidade" (RANCIÈRE,1998, p.221) é uma dimensão fundamental da participação. Mas a campanha, no que se refere ao envolvimento dos cidadãos em questões de gestão e políticas públicas, apresenta várias limitações. Isso pode ser constatado a partir dos dois pilares sobre os quais ela se apóia: a publicização dos atos dos representantes do poder público e a beleza de fragmentos da cidade que fazem parte do imaginário coletivo dos moradores. Ressaltamos ainda o fato de que a experiência dessas pessoas que aparecem nas peças publicitárias não pode ser tomada como síntese das experiências de todos os seus habitantes. Cada um tece e recria sua relação com o espaço onde vive e circula à sua maneira, ou à maneira de seu grupo ou comunidade.

A nosso ver, a narrativa oficial relegou a um segundo plano a narrativa da experiência cidadã, colocando em destaque a voz da prefeitura e não a do "personagem" retratado. Para captar a voz do cidadão e conhecer suas opiniões acerca da campanha, analisamos também o conteúdo de dois espaços do site oficial da campanha destinados à manifestação dos cidadãos acerca de dois temas: a) quem são elas e o que fazem para mostrar que gostam de $\mathrm{BH}^{8}$; e b) quais são as cinco coisas de $\mathrm{BH}$ que elas guardariam para o futuro ${ }^{9}$.

Neste artigo, serão exploradas mais detidamente as análises referentes às peças publicitárias que delineiam um "retrato" da cidade e da "participação" dos cidadãos em preservá-la, e as análises de alguns dos depoimentos dos cidadãos que se manifestaram no site a respeito da campanha.

\section{A comunicação pública e a participação}

O discurso elaborado pela prefeitura para explicar os motivos e preceitos que guiaram a campanha "Quem gosta de BH tem seu jeito de mostrar" é marcado pelo uso das noções de "cidadania", "participação", "corresponsabilidade",

\footnotetext{
8 Referente ao link: "O que você faz?" do site <www.pbh.gov.br/quemgostadebh>.

9 Referente ao link: "Guardar BH" do site <www.pbh.gov.br/quemgostadebh>.
} 
"iniciativa", "solidariedade", "trabalho", "dignidade" e de "um movimento de todos para todos"10. A mudança das estratégias discursivas da Prefeitura resulta da tentativa por ela empreendida de reelaborar sua comunicação com a sociedade civil. A Prefeitura de Belo Horizonte afirmava investir em uma comunicação que não fosse somente a "guardiã de sua imagem", mas também um elo de aproximação entre governantes e governados:

"A comunicação política em uma administração democrático-popular pode ser definida como um conjunto de estratégias e de ações táticas que visam a dar visibilidade aos projetos, programas e atividades do governo e reforçar-Ihes a imagem, sob a ótica da transparência e do interesse público. Essa tarefa se faz em um contexto delimitado por duas lógicas que se complementam, muitas vezes, de forma tensa. Primeiro, a lógica da conscientização popular, do diálogo entre iguais, da transparência e do pluralismo; a seguir, a lógica do ataque aos adversários políticos, da cobrança da imprensa, muitas vezes justa, mas muitas vezes simplificada e editorializada. (...)A comunicação do governo municipal de $\mathrm{BH}$ vem rompendo com antigas características que a tornavam menos eficaz. A primeira delas é o uso da comunicação apenas como instrumento reativo, "apagador de incêndios" em momentos de crise"(Revista Construir BH, 2003, p.41)

Ora, sabemos que a simples alteração ou o simples "retoque" de estratégias discursivas governamentais não são capazes de alterar todo um quadro de precário envolvimento dos cidadãos com atividades políticas que exigem engajamento e participação. Principalmente, se considerarmos dois grandes empecilhos clássicos: a) a cultura política clientelista que ainda opera em nossa sociedade; e b) o hiato existente entre as concepções de "participação" apresentadas pela sociedade civil e pelo governo municipal. Afinal, o que é participar? Nas peças de divulgação da campanha, encontramos uma definição que se aproxima a formação de um grande mutirão em prol da melhoria da qualidade de vida na cidade:

"Existe hoje no mundo uma forte corrente de valorização da vida e recuperação da paz e da dignidade das pessoas. Dessa forma, governos, empresas, cidadãos e organizações estão, cada vez mais, compartilhando responsabilidades na promoção da cidadania. (...) Com um plano de ação integrado e contínuo, centrado nos programas

10 Ver a Revista Construir BH, 2003. 
e exemplos dos agentes envolvidos, o movimento tem como tema a participação e as atitudes a favor da vida." (folder da campanha).

Mas engajar-se em um mutirão significa participar? Para algumas das pessoas que registraram sua opinião no site criado pela prefeitura para a divulgação da campanha ${ }^{11}$, o fato de se envolverem em mutirões significava que elas estavam "participando", de alguma forma, da melhoria da cidade:

Mesmo com tudo de ruim que vejo acontecer (no que diz respeito às questões ambientais) tento superar fazendo a minha parte. Uma delas é reciclando todo o lixo produzido na minha casa (Carla Gomes Franco) ${ }^{12}$.

As minhas ações são de uma belo-horizontina cidadã, que procura cuidar do que ama, como se cuida de um ser amado. Não poluo as ruas, trato bem as pessoas, não destruo nosso patrimônio e, principalmente, ensino às pessoas a fazerem o mesmo (Cristina G. F. Souza) ${ }^{13}$.

Os depoimentos acima revelam uma confusão entre civilidade, cidadania e participação. As três noções expressam coisas bastante diferentes. Vamos nos ater, contudo, ao conceito de participação. Para Georges Gontcharoff, a participação deve indicar uma partilha do poder, ainda que parcial ou reduzida:

"As verdadeiras instâncias participativas da sociedade civil são aquelas que dispõem de uma porção do poder de decisão delegada pelos eleitos e podem sentir-se autores de uma autêntica co-decisão, por exemplo através da gestão do orçamento de uma determinada região, ou através da adoção de um projeto regional, sobre o qual o poder municipal aceite ser parceiro. A participação está situada no campo da deliberação coletiva e não somente no domínio da instrução. Resta saber como o poder local elabora suas decisões com os cidadãos" (destaques nossos) (GONTCHAROFF, 1999, p.313).

\footnotetext{
${ }^{11}$ No site existem dois espaços específicos para que as pessoas possam se manifestar a respeito de dois temas: a) quem são elas e o que fazem para mostrar que gostam de $\mathrm{BH}$; e b) quais são as cinco coisas de $\mathrm{BH}$ que elas guardariam para o futuro. Este último tema é o mote do projeto Guardar $\mathrm{BH}$, que reuniu em um livro as opiniões coletadas do site, de onde extraí os depoimentos citados.

12 Depoimento extraído do site da campanha <www.pbh.gov.br/quemgostadebh>, no link "O que você faz?".

13 Idem.
} 
Participar, portanto, envolve uma atitude conflitiva de argumentação, de esclarecimento de referências respectivas e de construção de representações coletivas que permitem opor ou aproximar os pontos de vista (BLONDIAUX, 2001). Mesmo porque, como ressalta Leonardo Avritzer, "em um processo cooperativo de interpretação, ninguém possui o monopólio da interpretação correta" (AVRITZER, 2000, p.38).

A participação apresenta, assim, uma relevante dimensão de construção colaborativa de informações e saberes capazes de se complementarem e de produzirem soluções que se adequem às necessidades da maioria dos concernidos. Assim, "quem gosta de BH" deveria reivindicar, ao mesmo tempo, uma participação a uma comunidade de sentimento, e uma participação no processo de definição da melhor maneira de refletir, argumentar e dar visibilidade a soluções de interesse coletivo.

Mas, para que o processo participativo se consolide, duas coisas se fazem necessárias: a) uma dinâmica de negociação entre representantes e representados na qual a linguagem comum não seja a do "espetáculo", mas, sim, a linguagem cotidiana das necessidades e das lutas pela construção da cidadania; e b) a compreensão de que "o segredo primordial de uma 'boa cidade' é a oportunidade que ela dá às pessoas de assumir responsabilidade por seus atos 'em uma sociedade histórica imprevisível' e não 'em um mundo onírico de harmonia e ordem predeterminada" (BAUMAN, 2002, p.54).

\section{A distribuição hierárquica do poder e da palavra: alguns dilemas da participação}

Existem grupos que, pela função ou lugar que ocupam no corpo social, têm sua parte assegurada na partilha do poder e dos espaços de fala: governantes, empresas, instituições, especialistas, etc. Outros, porém, não são considerados como sujeitos aptos a expressar ou argumentar sobre o que veem ou o que vivem. Nessa perspectiva, que muito lembra a noção de tecnocracia desenvolvida por Schumpeter (1971), cabe-nos perguntar: quem pode fazer parte dos processos participativos? Quais discursos figuram no espaço destinado aos fóruns deliberativos? A palavra do prefeito ou a palavra do cidadão? Afinal, participar é intervir diretamente nas decisões ou é fazer com que sua opinião conte nos processos argumentativos? Qual o melhor caminho para traçar uma reconfiguração do plano sensível de distribuição da palavra, dos espaços de visibilidade e de atividades dos habitantes de $\mathrm{BH}$ ?

No site criado para divulgar a campanha "quem gosta de $\mathrm{BH}$ tem seu jeito de mostrar" encontramos, entre outros, os seguintes links: "Empresas cuidam de BH", "PBH cuida de BH", "Instituições cuidam de BH" e "O que você faz ?". Nesses 
MARQUES, A. C. S. Comunicação, mídia e processos de democracia...

espaços estão relacionadas as empresas e instituições que atuam em parceria com a prefeitura, os projetos que possuem destaque na campanha e um espaço para a escrita de mensagens onde cada cidadão é incentivado a relatar sua forma de participação e atuação no seu bairro, escola, quarteirão, enfim, no espaço de sua experiência cotidiana. Essa divisão mostra, de um lado, as partes da comunidade que têm acesso à visibilidade, à palavra e aos espaços da cidade: prefeitura, empresas e instituições. $E$, de outro lado, se concentra uma categoria extremamente heterogênea e "sem nome", e portanto, em princípio sem existência e sem palavra: você.

Sabemos que há uma configuração sensível dos modos de ser, fazer e dizer que determina hierarquização simbólica dos homens e de seus discursos (RANCIÈRE,1995). Para participar, cada um precisa diferenciar-se, fazer "algo a mais". Assim, a pergunta-link "O que você faz?" certamente não pode ser traduzida como "Qual é seu trabalho?" ou "Qual a sua principal ocupação?", mas sim como "Qual a outra atividade que você faz e que te torna singular, visível e apto à participar das coisas comuns?". Sendo assim, quem gosta de BH deve encontrar um tempo e um espaço, fora de sua ocupação tradicional, para tomar parte do mundo comum. Seja participando do Orçamento Participativo, seja ensinando dança aos meninos e meninas de uma favela:

"Sou estudante universitária e participo de um projeto de extensão chamado "O Sal da Terra». (...)O objetivo do nosso projeto é promover a melhoria da qualidade de vida e incentivar a cidadania junto aos alunos da Escola Municipal Santos Dumont através de oficinas, jogos, palestras e o cultivo de uma horta localizada atrás da escola. O projeto tem como parceiros a FUMEC, a Belotur e outras instituições e empresas" (Fernanda Júnia).

"Sou Fisioterapeuta da PBH e professora do curso de Fisioterapia da PUC Minas. Além de desenvolver o meu trabalho como servidora pública, supervisiono, juntamente com outros professores (alguns deles também servidores), o estágio de fisioterapia na área de saúde coletiva em centros de saúde (Juliana Maciel Gomes)" ${ }^{14}$.

A atividade política - que funciona sob a lógica da "igualdade de qualquer ser falante perante qualquer outro ser falante" (RANCIÈRE,1995, p.53) - contesta a designação de um lugar específico aos indivíduos dentro do sistema trabalho/lazer/cultura e aponta para uma reinvenção das práticas que permitem

14 Os depoimentos utilizados nessa seção do artigo foram extraídos do site da prefeitura dedicado à campanha: <www.pbh.gov.br/quemgostadebh> no link: "O que você faz?". 
aos indivíduos se expressarem e se construírem como sujeitos e como membros de uma coletividade.

Para participar das reuniões do Orçamento Participativo ou para resgatar a dignidade de meninos de rua através da arte é preciso colocar em questão a "distribuição de maneiras de ser e das ocupações dentro de um espaço de possíveis" (RANCIĖRE,2000, p.66). Ou seja, é preciso deslocar as pessoas de seus lugares "supostos" na comunidade e fazer com que elas tenham acesso e tomem parte daquilo que diz respeito a todos. A participação, enquanto desafio a essa hierarquização, possui também um sentido de exploração e reconhecimento das potencialidades "escondidas" de cada um (BAIERLE, 2000).

É preciso enfatizar que a campanha não deixa claras as clivagens, hierarquizações e assimetrias entre aqueles que podem participar ou não da gestão da cidade. Muito pelo contrário, visto que o objetivo da campanha é mostrar que todos - empresas, instituições privadas, pessoas comuns, governo, etc. - são efetivos parceiros dessas atividades que buscam construir uma $\mathrm{BH}$ ideal de se viver, sua intenção era formar um "movimento" ou uma "corrente de participação comunitária" capaz de ser "o alicerce da construção de uma cidade melhor" (Revista Construir BH, 2003).

A campanha é bela e fala da beleza, nunca da desarmonia, da assimetria e da desorganização. Todavia, quem mora em $\mathrm{BH}$ e, todos os dias, percorre suas ruas, lugares e espaços, relata experiências bem diversas daquelas estampadas nos anúncios publicitários da campanha:

Belo Horizonte é a minha cidade. É aqui que enfrento o desafio diário de encontrar soluções para cada conflito que um cidadão tem pela frente. A cada amanhecer, os ruídos da cidade me projetam da cama e após os ônibus lotados, as calçadas esburacadas e sujas, um trânsito confuso; após as idas e vindas de um dia de trabalho, pasando por uma paisagem urbana poluída e pelas vilas e favelas cada vez mais habitadas e sem perspectivas, é preciso continuar acreditando que ainda existe um Belo Horizonte (Raimundo Machado Filho).

Como mencionamos anteriormente, um olhar mais atento sobre a campanha "Quem gosta de BH tem seu jeito de mostrar" revela uma Belo Horizonte isenta de conflitos e tensões, de espaços sujos, escuros ou abandonados. Seus lugares de opacidade são estrategicamente desconsiderados para dar lugar a uma $\mathrm{BH}$ muito ordenada, muito clara, muito fácil de entender. Por isso, a $\mathrm{BH}$ ideal, ou, mais precisamente, "a BH que a gente quer" transmite "tudo em um lampejo, como um bom anúncio publicitário" (JACOBS, 2000, p.23). 
MARQUES, A. C. S. Comunicação, mídia e processos de democracia...

Assim, a própria definição da campanha revela que "todos" estão envolvidos, em igualdade de condições, na construção de uma cidade onírica, que só existe enquanto projeto utópico, pois o espaço cindido das hierarquias coloca-se, constantemente, como obstáculo à igualdade de status e de oportunidades. A ideia de participação contida na campanha não menciona o tipo de participação construída nos espaços de embate e conflito, onde as pessoas se encontram, estabelecem diálogos e contatos, permitindo a troca renovada de impressões e pontos de vista (TELLES, 1994).

Para não sermos totalmente pessimistas, existem projetos, como o Orçamento Participativo que, embora não possam ainda ser considerados fóruns em que as assimetrias foram totalmente extintas, estão contribuindo para um crescente processo de aprendizagem que inclui, além de uma concepção ampliada da cidadania, um ganho epistêmico relativo à troca de argumentos e pontos de vista em público (PAOLI \& TELLES, 2000). As pessoas estão aprendendo a ouvir e a serem ouvidas, modificando suas premissas enquanto reformulam suas demandas, questionam as autoridades e desenvolvem suas identidades. Afinal, o confronto com os outros, sejam eles governantes, especialistas ou nossos vizinhos, é sempre um processo dinâmico de produção de um autoentendimento e de um entendimento da situação do outro (HABERMAS, 1997; BOHMAN,1996; MARQUES, 2008).

O panorama anteriormente apresentado nos leva a interpretar a cidade como sendo, ao mesmo tempo, um espaço público de lutas e discussões, "cena pública" que garante visibilidade aos projetos e conflitos sociais, e "lugar de produção e partilha de uma comunidade" que circula, comunica e se reapropria constantemente dos tempos e espaços que definem a trama sensível de relações cooperativas que se estabelecem por meio da linguagem.

\section{Considerações Finais}

Este artigo mostrou que a campanha "Quem gosta de $\mathrm{BH}$ tem seu jeito de mostrar" é o resultado de uma estratégia comunicativa da prefeitura da cidade para fazer crer aos seus habitantes que eles estão inseridos em uma teia participativa que visa melhorar a qualidade de vida do espaço urbano.

Também mostrou que a participação e a cidadania, tal como expressas na campanha, ao invés de conquistadas em um processo comunicativo de embate, aparecem como questão organizada pelas elites políticas, ou seja, é a prefeitura que determina espaços de expressão onde cada "parceiro" procurará inserir sua contribuição. Ao eliminar o conflito, a campanha restringe as possibilidades de cada cidadão sentir-se reconhecido ao questionar a desigualdade de posições que o afastam da vida política. Mas é justamente aí, nessa aparente ordem do inquestionável, que se encontra a cilada: se todos parecem estar potencialmente 
incluídos, para que eles vão se dar ao trabalho de engajar-se em processos participativos? Sendo assim, a campanha não se mostra mais como mobilizadora, mas como um projeto desmobilizador.

Vimos que a campanha, ao invés de diminuir as assimetrias comunicativas entre especialistas, empresários, políticos e atores cívicos, privilegia a palavra que já tem sua força constituída. Agindo assim, a prefeitura afasta as pessoas dos processos de governança centrada na negociação e deliberação inclusiva. A campanha apaga não só a palavra dos pobres, como a própria presença dos pobres na cidade, descartando a diversidade em troca da obviedade e, por consequência, restringindo as vias da intersubjetividade e da interação (SANTOS,1997, p.323). Sob essa ótica, a campanha homogeneiza tanto a cidade quanto seus cidadãos, negando-Ihes o devido respeito (SENNETT, 2003).

As pessoas só se engajam em processos participativos quando motivadas pela certeza de que sua contribuição específica poderá alterar o rumo e a formulacão de políticas e normas que as afetam diretamente. Participar adquire, então, dois sentidos principais: reestruturar as relações argumentativas entre "centro" e "periferia" e perceber a atividade dos cidadãos como algo que realmente pode influir nos processos políticos. Enfim, a campanha, que deveria ser um canal aberto para que o poder administrativo se posicionasse como ouvinte e interlocutor da sociedade civil, acabou limitando a expressão das pessoas aos motivos afetivos que as fazem gostar de $\mathrm{BH}$.

Um outro empecilho à participação pode ser expresso pelo próprio caráter não-problemático da campanha, que se baseia no estreitamento do vínculo social para atrair seu público-alvo: um cidadão-modelo, "participativo", que cumpre seu papel dentro dos preceitos da boa civilidade. Sendo assim, a campanha "Quem gosta de BH tem seu jeito de mostrar" pode ser caracterizada como "politicamente correta", afinal quem pode discordar de seus conteúdos? Ao definir "quem gosta de $\mathrm{BH}$ " e "como gosta", a campanha da prefeitura acaba por restringir a participação política em troca do fortalecimento da memória afetiva e da produção social da proximidade (BOURDIN, 2001).

Gostar de BH não pressupõe, portanto, uma partilha de responsabilidades que determine processos deliberativos responsáveis pela definição de uma boa gestão política da cidade. O que a formulação da campanha nos revela é que são as elites políticas que continuam definindo a dimensão e as regras de interseção entre a democracia participativa e a democracia representativa. Afinal, dizer qual é o espaço que você ocupa na cidade e em que condições deve atuar dentro desse espaço determinado é uma forma de poder que está bem distante do ideal de poder compartilhado. Esse último não se confunde com a autoridade, mas "supõe uma relação em que atores, utilizando recursos disponíveis nos espaços públicos [inclusive a mídia], fazem valer seus interesses, aspirações e valores, construindo 
suas identidades, afirmando-se como sujeitos de direitos e obrigações" (TEIXEIRA, 2000, p.37).

É importante ressaltar que o papel da comunicação e da mídia em processos de democracia local não deve ser atrelado somente à comunicação institucional. Atualmente, são as possibilidades trazidas pelas mídias que potencializam a capacidade deliberativa da democracia local. Isto não significa que a mídia produz por si mesma relações democráticas, mas ela pode se tornar um fórum pluralista de debate quando encampa as diferentes vozes e conflitos que perpassam o local e repercutem nos âmbitos nacional, regional e internacional (MAIA, 2004; MARQUES, 2008). Se considerarmos que a democracia local é o campo onde se cruzam a diversidade dos engajamentos, dos atos e pontos de vista, podemos compreender o motivo da relevância das mídias nesse processo, uma vez que é por meio delas que o debate é congregado e, muitas vezes formulado. É através da mídia e de seus processos reflexivos de visibilidade que um espaço local de debate democrático pode ser instaurado, promovendo um relação interlocutiva entre os cidadãos e as instituições formais (LOISEAU, 2002; MIGUEL, 2002).

Como vimos, a atitude participativa ultrapassa ações corriqueiras e pontuais, como os mutirões, e se inscreve nas práticas dos cidadãos como um aprendizado e uma consciência do "tomar parte" e "ser parte" de um processo democrático em contínua transformação.

\section{Referências Bibliográficas}

AUBELLE, V. "Le sens de la démocratie locale". In: Centre Universitaire de Recherches administratives politiques de Picardie (CURAPP) \& Centre de Recherches administratives politiques et sociales de Lille (CRAPS) (orgs.). La Démocratie Locale - Représentation, Participation et Espace Public. Paris: Presses Universitaires de France, p.271.301, 1999.

AVRITZER, L. “Teoria democrática e deliberação pública”. Lua Nova, n50, p.25·46, 2000.

AVRITZER, L. e PEREIRA, M. L. D. "Democracia, participação e instituições híbridas", mimeo, 2002. 
BAIERLE, S. G. A explosão da experiência: emergência de um novo princípio ético-político nos movimentos populares urbanos em Porto Alegre. In: ALVAREZ, S.; DAGNINO, E.; ESCOBAR, A. (orgs.). Cultura e Política nos Movimentos Sociais Latino-Americanos: novas leituras. Belo Horizonte: Ed. UFMG, 2000.

BAUMAN, Z. Globalização: as consequências humanas. Rio de Janeiro: Zahar, 2002.

BLONDIAUX, L. "Representer, Delibérer ou Governer? Les assises politiques fragiles de la démocratie de quartier". In: Centre Universitaire de Recherches administratives politiques de Picardie (CURAPP) \& Centre de Recherches administratives politiques et sociales de Lille (CRAPS) (orgs.). La Démocratie Locale - Représentation, Participation et Espace Public. Paris: Presses Universitaires de France, p.367-404, 1999.

"Démocratie locale et participation citoyenne: la promesse et le piège".

Mouvements, n.18, nov.-déc., p.44-51, 2001.

BOHMAN, J. Public Deliberation: pluralism, complexity, and democracy. Massachusetts: Mit Press, 1996.

BOURDIN, A. A questão local. Rio de Janeiro: DP\&A, 2001.

COGO, D. M. No ar... uma rádio comunitária. São Paulo: Paulinas, 1998.

COSTA, S. "Movimentos Sociais, democratização e a construção de esferas públicas locais". Revista Brasileira de Ciências Sociais, vol.12, n³5, outubro, p.121-134, 1997.

DAGNINO, E. Sociedade civil, espaços públicos e a construção democrática no Brasil: limites e possibilidades. In: DAGNINO, E. (org.). Sociedade Civil e Espaços Públicos no Brasil. São Paulo: Paz e Terra, 2002. 
DAUVIN, P. "Region, communication, citoyenneté: une équation introuvable?". Pouvoirs Locaux - les cahiers de la décentralisation, vol.1, n52, p.53-56, 2002.

GOHN, M. G. Conselhos Gestores e Participação Sócio-Política. Rio de Janeiro: Cortez, 2001.

GOLDSTEIN, M. N. "L'éthique de la discussion au service d'une nouvelle politique de la ville: l'éxperience de Antanas Mockus à la mairie de Bogota". Quaderni, n49, p.119.133, 2003.

GONTCHAROFF, G. "Le Renouveau des Comités de Quartier". In: Centre Universitaire de Recherches administratives politiques de Picardie (CURAPP) \& Centre de Recherches administratives politiques et sociales de Lille (CRAPS) (orgs.). La Démocratie Locale Représentation, Participation et Espace Public. Paris: Presses Universitaires de France, p.305-327, 1999.

GUTMANN, A. e THOMPSON, D. "Deliberative democracy beyond process". The Journal of Political Philosophy, vol.10, n², p.153-174, 2002.

HABERMAS, J. "Participação Política”. In : CARDOSO, F. H. ; MARTINS, C. E. (orgs.). Política e Sociedade, vol.1. Rio de Janeiro : Companhia Editora Nacional, 1979.

The Theory of Communicative Action -Lifeworld and system: a critique of functionalistic reason. Boston: Beacon Press, 1987.

- "Soberania popular como procedimento: um conceito normativo de espaço público". Novos Estudos Cebrap, n²6, p.100-113, 1990.

Direito e Democracia: entre facticidade e validade. Vol II. Rio de Janeiro: Tempo Brasileiro, 1997.

JACOBS, J. Morte e Vida de grandes cidades. São Paulo: Martins Fontes, 2000. 
LE BART, C. "La cité idéale des journaus territoriaux". Pouvoirs Locaux - les cahiers de la décentralisation, n52, vol.1, p.45-48, 2002.

MAIA, R. C. M. Dos dilemas da visibilidade midiática para a deliberação política. In: LEMOS, A. et al.(orgs.). Livro da XII Compós: Mídia.br. Porto Alegre: Sulina, p.9-38, 2004.

"A mídia e o novo espaço público: a reabilitação da sociabilidade e a formação discursiva da opinião". Comunicação \& Política, vol.5, nº1, jan.-abr., p.131-156, 1998.

MARQUES, A. L'intersection entre le processus communicatif et la délibération publique, [on line]. 2008, disponível em: <http://w3.u-grenoble3.fr/les enjeux/2008/Marques/index.php>. Accesso em: 10 nov. 2008.

MATOS, H. "Comunicação Política e Comunicação Pública", Revista Organicom, ECA/USP, nº 4, 2006.

MÉGARD, D. "Communication publique, médias et démocratie". Pouvoirs Locaux - les cahiers de la décentralisation, vol.1, n52, p.40-44, 2002.

MIGUEL, L. F. “Os meios de comunicação e a prática política”. Lua Nova, n55-56, p.155-184, 2002.

OLIVEIRA, V. C. "Comunicação, identidade e mobilização na era da informação". In: PERUZZO, C. e BRITES, J. (orgs). Sociedade da Informação e novas mídias: participação ou exclusão ? São Paulo: Intercom, 2002.

"Comunicação, participação popular e controle público no sistema único de saúde". Mimio, 2004. 
PAILLIART, I. "Les enjeux locaux de la démocratie électronique". Hermès, n 26-27, p.129. $140,2000$.

PAOLI, M. C. e TELLES, V. S. Direitos Sociais: conflitos e negociações no Brasil contemporâneo. In: ALVAREZ, S.; DAGNINO, E. e ESCOBAR, A. (orgs.). Cultura e Política nos Movimentos Sociais Latino-Americanos: novas leituras. Belo Horizonte: Ed. UFMG, 2000.

PEREIRA, M. L. D. "Negociações e parcerias: o desafio da gestão urbana democráticoparticipativa". Teoria \& Sociedade, vol.6, p.212-241, 2000.

Repensando as relações entre espaço urbano e cidadania. Aqui Arquitetura + Cultura. Belo Horizonte: Ed. Ao Cultural, n³, 2002.

PORTO, M. “Mídia e deliberação política: o modelo do cidadão interpretante". Política e Sociedade, n.2, p.67-108, 2003.

QUÉRÉ, L. "Communication Sociale: les effets d'un changement de paradigme". Reseaux, n.34, p.21-47, 1989.

RANCIÈRE, J. Le tort: politique et police. In: RANCIÈRE, J. La Mésentente - politique et philosophie. Paris: Galilée, 1995.

Aux bords du politique. Paris: La Fabrique-Éditions (Folio, Gallimard), 1998.

Le Partage du Sensible, esthétique et politique. Paris: La Fabrique, 2000.

SANTOS, M. A Natureza do Espaço: técnica e tempo, razão e emoção. São Paulo: Hucitec, 1997.

SCHUMPETER, J. A. Capitalismo, socialismo e democracia. Rio de Janeiro: Zahar, 1971. 
SENNETT, R. Respect: de la dignité de l'homme dans un monde d'inegalité. Paris: Albin Michel, 2003.

STEWART, J. "Democracy and local government”. In: HIRST, P. e KHILNANI, S. (eds.). Reinventing Democracy. Cambridge: Blackwell, p.39-56, 1996.

TEIXEIRA, E. C. Sociedade Civil e Participação Cidadã no Poder Local. Salvador: Pró-Reitoria de Extensão da UFBA, 2000.

TELLES, V. S. Sociedade civil e a construção de espaços públicos. In: DAGNINO, E. (org.). Os Anos 90: política e sociedade no Brasil. São Paulo: Brasiliense, 1994.

WOLTON, D. "Le Local, la petite madeleine de la démocratie". Hermès, n²6-27, p.89-97, 2000.

Angela Cristina Salgueiro Marques - angelasalgueiro@gmail.com

Recebido para publicação em março de 2008. Aprovado para publicação em novembro de 2008. 